\title{
An Innovative B2C E-commerce Websites Selection using the ME-OWA and Fuzzy AHP
}

\author{
Anu G. Aggarwal, Aakash \\ Department of Operational Research, University of Delhi, Delhi, India \\ \{anuagg17, aakash.du.or50\}@gmail.com
}

\begin{abstract}
Today internet has emerged as a huge marketplace of products and services for meeting needs of more than a million customers worldwide. It provides users a platform to access information globally in electronic form as well as in terms of business transaction, such as,e-payments, e-orders and e-booking etc. The advent of the internet has led to the establishment of electronic commerce. Today a large number of B2C e-commerce websites are available, which makes it difficult not only for the customers to find right product at right price, but also for a company to choose a better site for selling its product. Thus, there is need to rank e-commerce websites in $\mathrm{B2C}$ electronic commerce. The objective of this paper is to rank ecommerce websites on the basis of success factors, namely, System Quality, Content Quality, Usages, Trust, Customer Support, Online Customer Feedback and Personalization. Here we have used a two stage approach combining maximum entropyordered weighted averaging aggregation (ME-OWA) with fuzzy Analytic Hierarchy Process (FAHP) for choosing the best B2C e-commerce website.
\end{abstract}

Index Terms-Customer Oriented Success Factors, E-commerce, Fuzzy Set, Fuzzy AHP, Fuzzy ME-OWA

\section{INTRODUCTION}

$\mathrm{N}$ OW A days, business organization use e-commerce system to communicate with their customers and to provide online business transactions. With the deep penetration, e-commerce is in use. To sustain the cut-threat competition market, it has become essential for business to direct towards online business platforms. Now combination of business and internet has become necessary for B2C e-commerce organizations to coordinate with their customer and stockholders. Business-to- consumer (B2C) e-commerce website is a used to communicate with customers and to provide business transactions. The e-commerce has grown continuously all over the world, its growth has occurred in both the countries either it developed or it is developing, which is the reason for increase in the online shopping community in the world [1].

The success of any business organization depends on the customer satisfaction level. Similarly, the success of B2C ecommerce also depends upon the customer satisfaction towards e-commerce websites. In this paper, we propose a framework based on maximum entropy ordered weighting averaging operator (ME-OWA) and fuzzy AHP to select the best $\mathrm{B} 2 \mathrm{C}$ e-commerce website on the bases of customers oriented success factors. The ME-OWA is used for calculat- ing the orness weights of evaluation criteria and fuzzy AHP is used for calculating the weight vector for alternatives respect to each criterion. The weights so obtained are used to rank the alternative through ordered weighted averaging aggregation (OWA) operator.

This paper is organized as follows: Section 2 gives the detailed research background. The methodology used in this paper has been described in the Section 3. The application part of the proposed methodology is shown in the Section 4. Section 5 concludes the paper.

\section{Research Background}

More than two decades ago DeLone and McLean initially proposed information system (IS) success model [2]. This is the iconic model in the area of success measurements that has found vast application in many domains which includes business education, human resource management, etc. The major dimensions of information system success were system quality, information quality, use, user satisfaction, individual impact, and organizational impact. This model provides a basis for evaluating the performance of information systems. Later in 2001, Molla and Licker (M\&L) shown that IS success model can be used for identifying the success of e-commerce system [3]. They highlighted the significance of customer satisfaction and their experience, towards ecommerce system. M\&L defined trust as additional factor. The main factors of M\&L's model were content quality, system quality, use and user satisfaction, support \&service, and trust. As compared to DeLone and McLean's(D\&M) IS success model, the M\&L's model used content quality instead of information quality, user satisfaction for e-commerce customers, service in the place of service quality, and trust added as a new factor in $\mathrm{B} 2 \mathrm{C}$ e-commerce environment.

DeLone and McLean updated their IS success model after a decade in 2002 with additional success factors intention to use, use and net benefits, and further extended in 2003.Themain elements included by them were information quality, system quality user satisfaction, intention to use, use, net benefits, and service quality [4] [5]. Delone and McLean demonstrated that D\&M's updated IS success model could be used for evaluating the e-commerce success without any changes [6]. This model is based on the updated D\&M's IS 
success model in 2002 and extended in 2003. The success dimension of DeLone and McLean (2004) model used for evaluating the e-commerce success are system quality, information quality, service quality, usage, user satisfaction, and net benefits [6].

Todays' B2C e-commerce world has many features which can affect the B2C e-commerce success such as: customer feedback and personalization. Customer feedback is a crucial factor now days, measured in terms of online reviews, ratings [7], and helpfulness [8]. Personalization is defined as the customization of products and services in accordance to the user needs [9]. This factor depends on a number of attributes such as individual preferences, cross-selling and up-selling for evaluating the success of $\mathrm{B} 2 \mathrm{C}$ e-commerce. Therefore, there is a growing need to extend the previous $\mathrm{B} 2 \mathrm{C}$ e-commerce success model with these latest B2C e-commerce success factors. Overall, we have included seven success criteria where five criteria namely system quality "(SQ)", content quality "(CQ)", Usage "(US)", Trust "(TR)", customer support "(CS)" are same as specified by D\&M [6].

The two additional success criteria included in the proposed model are customer feedback "(CF)" and personalization "(PR)". At present a large number of B2C e-commerce websites are offering wide range of products with many promotional schemes and pricing policies, which makes it difficult not only for the customers to find the right product at the right price, but also for a supplier to choose a best site for selling its product. Thus, selection of $\mathrm{B} 2 \mathrm{C}$ e-commerce websites is crucial and it is important for both customers and company. The main focus of this paper is to select best $\mathrm{B} 2 \mathrm{C}$ e-commerce website on the basis of our extended B2C ecommerce success model with seven success criteria. As, this problem is multicriteria decision making problem, therefore, we use MCDM techniques, namely OWA operator, MEOWA, and fuzzy AHP. The detailed methodology of these techniques is explained in the next section.

\section{METHODOLOGY}

The methodology used in this paper is described as follows:

(1) The OWA: The ordered weighted averaging aggregation operator (OWA) is a part of multi-criteria family, and it is given by Yager [10]. The main purpose of using OWA operators is to take full benefits of the available information and to remove the overestimation of decision maker's priorities. The ordered weighted averaging operators used in this paper are as follows:

Definition 1. An OWA operator of dimension $\mathrm{n}$ is defined as mapping $\mathrm{F}$

$$
F: Z^{n} \rightarrow Z(\text { where } Z=[0,1])
$$

with weight vector $(W)=\left(w_{1}, w_{2}, \ldots \ldots \ldots, w_{n}\right)^{T}$

such that

$$
\text { I. } \quad w_{i} \in(0,1) \forall i=1,2, \ldots \ldots, n \text {. }
$$

II. $\quad w_{1}+w_{2}+\cdots \ldots .+w_{n}=1$

and where

$$
\begin{array}{r}
F\left(a_{1}, a_{2}, \ldots \ldots ., a_{n}\right)=w_{1} b_{1}+w_{2} b_{2}+\cdots \ldots \ldots \ldots+w_{n} b_{n}= \\
\sum_{i=1}^{n} w_{i} b_{i}=W B(1)
\end{array}
$$

where $\mathrm{B}$ be the ordered argument vector given by $B=$ $\left(b_{1}, b_{2}, \ldots \ldots, b_{n}\right)$ and $b_{i}$ is the $i^{t h}$ largest element in the set $\left\{a_{1}, a_{2}, \ldots \ldots, a_{n}\right\}$, which are arranged in descending order (i.e., $b_{1} \geq b_{2} \geq \cdots \ldots \geq b_{n}$ ) before calculating the scalar product with weight vector $W$.

Definition 2. Let $F$ be an OWA operator and $W$ be the weight vector given by $W=\left[w_{1}, w_{2}, \ldots \ldots, w_{n}\right]^{T}$, then the degree of "Orness"associated with $F$ is defined as:

$$
\operatorname{orness}(W)=\frac{1}{(n-1)} \sum_{i=1}^{n}(n-i) w_{i}=\beta
$$

Here $\beta \in[0,1]$. If the value of "orness $(W)$ "i.e. $\beta$ is close to one then relationship between multiple attributes shows higher orlike leveli.e. $0.5 \leq \beta \leq 1$, while if it is close to zero then higher andlike leveli.e. andness $(W)=1-\beta$. Oring the multiple attributes means the decision maker is maximally optimistic but anding the multiple attributes means the decision maker is maximally noncommittal. Thus, as we move weight up, we increase the orness, while moving weight down causes decrease in the orness. Specifically,if $w_{i}=1 / n \forall i=1,2, \ldots, n$, then the value of $\operatorname{orness}(W)=0.5$. In that case, the decision maker has a medium assessment.

Definition 3. For a given weight vector $W=\left(w_{1}, w_{2}, \ldots \ldots \ldots, w_{n}\right)^{T}$, the measure of entropy (or dispersion) is defined as:

$$
\operatorname{dispersion}(W)=-\sum_{i=1}^{n} w_{i} \ln w_{i}
$$

In particular, if $w_{i}=1$ for some $i$, and $w_{j}=0(\forall j \neq i)$, then thedispersion of weight vector $W$ is minimum i.e.dispersion $(W)=0$, it means that only one attribute is considered in the aggregation process and if $w_{i}=1 / n \forall i=1,2, \ldots n$; then dispersion of weight vector $W$ ismaximum i.e. $\operatorname{dispersion}(W)=\ln n$.It means that all the attributes are considered in the aggregation process.

(2) The ME-OWA: The ME-OWA operator was proposed by O'Hagan [11], its maximizes the entropy of weight vector (W) subject to orness of weight vector (W). The mathematical formulation for this problem is given as follows: 


$$
\begin{aligned}
& \text { maximize }-\sum_{i=1}^{n} w_{i} \ln w_{i} \\
& \text { s.t. } \frac{1}{(n-1)} \sum_{i=1}^{n}(n-i) w_{i}=\beta, \quad 0 \leq \beta \leq 1 \\
& \sum_{i=1}^{n} w_{i}=1, \quad 0 \leq w_{i} \leq 1, \quad i=1, \ldots \ldots, n .
\end{aligned}
$$

Fullér and Majlender used Lagrange multiplier method for determining the optimum weight vectors with respect to maximum entropy [12]. The associated weight $w_{i}, i=$ $1,2, \ldots, n$ corresponding to multiple attributes are given in Eqs.(5a)-(5c):

$$
\begin{aligned}
& \ln w_{j}=\frac{j-1}{n-1} \ln w_{n}+\frac{n-j}{n-1} \ln w_{1} \\
& \text { or } w_{j}=\sqrt[n-1]{w_{1}^{n-j} w_{n}^{j-1}}, \text { for } 1 \leq j \leq n
\end{aligned}
$$

wheren is the total number of attributes, and

$w_{n}=\frac{((n-1) \alpha-n) w_{1}+1}{(n-1) \alpha+1-n w_{1}}$

then $w_{1}\left[(n-1) \alpha+1-n w_{1}\right]^{n}=((n-1) \alpha)^{n-1}[((n-$ 1) $\left.\alpha-n) w_{1}+1\right]$

where the optimum value of $w_{1}$ should satisfy Eq. (4b) and is calculated using Eq. (5c), and then the optimal value of $w_{n}$ is obtained from Eq. (5b). Remaining weights are determined by Eq. (5a). For illustration, the weight vectors of ME-OWA operator for $n=7$ are given in Table 1 .

Table 1. The weight vectors $\left(w_{i}\right)$ of ME-OWA operator for $n=7$.

\begin{tabular}{lcccccc}
\hline & \multicolumn{7}{c}{$\beta$} & & & \\
\cline { 2 - 7 } & 0.5 & 0.6 & 0.7 & 0.8 & 0.9 & 1 \\
\hline$w_{1}$ & 0.1429 & 0.2158 & 0.3096 & 0.4353 & 0.6227 & 1 \\
$w_{2}$ & 0.1429 & 0.1852 & 0.2236 & 0.2497 & 0.2354 & 0 \\
$w_{3}$ & 0.1429 & 0.1589 & 0.1614 & 0.1433 & 0.0889 & 0 \\
$w_{4}$ & 0.1429 & 0.1364 & 0.1165 & 0.0821 & 0.0336 & 0 \\
$w_{5}$ & 0.1428 & 0.1171 & 0.0842 & 0.0471 & 0.0127 & 0 \\
$w_{6}$ & 0.1428 & 0.1004 & 0.0608 & 0.0270 & 0.0049 & 0 \\
$w_{7}$ & 0.1428 & 0.0862 & 0.0439 & 0.0155 & 0.0018 & 0 \\
\hline
\end{tabular}

(3) The fuzzy set theory: The fuzzy set theory was proposed by Zadeh to tackle the vagueness and uncertainty in decision making for enhancing precision [13]. So, the vague data may be represented by using fuzzy numbers which may be further subjected to mathematical functions in fuzzy domain. The fuzzy numbers are represented by membership function $\mu_{\widetilde{M}}(x)$ ranging between 0 and 1 . A triangular fuzzy numbers (TFNs) is shown in Fig. 1.

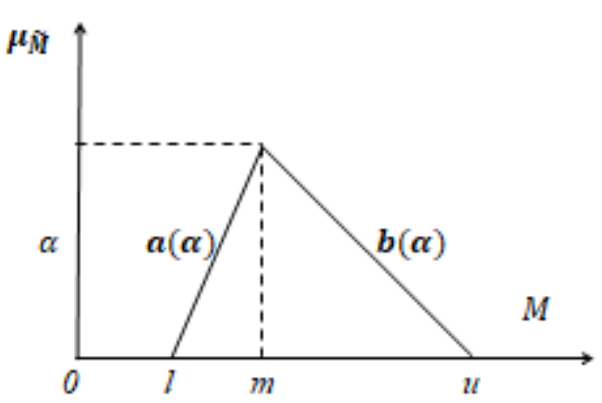

Fig. 1: Triangular Fuzzy Number (TFN)

A TFN is represented by $(1, \mathrm{~m}, \mathrm{u})$, where $1, \mathrm{~m}$, and $\mathrm{u}$ are the smallest, most promising, and largest possible values respectively. The linear representation of TFN can be shown a membership function.

$$
\mu_{\widetilde{M}}(x)=\left\{\begin{array}{cc}
0, & x<l \\
\frac{x-l}{m-l}, & l \leq x \leq m \\
\frac{\mu-x}{\mu-m}, & m \leq x \leq \mu \\
0, & x>\mu
\end{array}\right.
$$

The membership function for a TFN with linear representation of left and right side as is given by: $a(\alpha)=$ $l+\alpha(m-l) ; b(\alpha)=u-\alpha(\mu-m) ; \alpha \in[0,1]$

where $a(\alpha)$ and $b(\alpha)$ are left and right side representation of a TFN respectively.

(4) The Fuzzy AHP: The analytical hierarchical process (AHP) is a decision making technique, which is used to tackle complex multi-criteria problems involving both qualitative and quantitative decisions variables [14]. It is used for determining the priorities among the different criteria, alternative comparison with respect to each criterion, and determining the preference for each alternative. The detailed procedure is as follows: firstly, decision makers have to construct a hierarchal structure for their problem in which goal, criteria and alternative phases, are placed at different levels. After the hierarchical structure, the pair wise comparison matrix will be constructed through decision makers' judgment on the importance of each criterion. The importance is measured using Saaty's fundamental scale [14]. Next, we check the consistency of the decision matrices and then calculate the relative importance weights for criteria at each level of hirerachy using pair-wise comparison matrices. The final result is on relative basis by comparing the importance of one alternative to another.

The AHP is usually used to judge intangibles, but it does not fully include the importance of qualitative aspects because its fundamental scale cannot indicate the humans' way of thinking. According to Kwong and Bai, experts' judgments are affected by imprecision and uncertainty. Thus, the use of precise and definite numbers as a linguistic judgment is not much logical [15].

To overcome this difficulty, fuzzy AHP technique is used for 
optimal selection problem. Fuzzy AHP approach is the combination of triangular fuzzy number (TFNs) and analytical hirerachy process (AHP). It converts the linguistic judgments into the organized triangular fuzzy numbers (TFNs) for constructing fuzzy pair-wise comparisons matrices. These pair-wise matrices are used to get the weights of criterion and to rank the alternatives. Although there are a number of methods to tackle pair-wise matrices in fuzzy AHP such as: Buckley [16], Chang [17], Lee [18] etc. Out of all these, mostly used method is extent analysis method given by Chang [17]. This method is simple and effective to calculate the relative weights of the criteria and alternatives. In this paper, we have used Chang's extent analysis method to get the crisp weights of criteria and alternatives. The conversion scale, used for converting the linguistic judgments into the TFNs [19], is given in Table 2.

Table 2: Triangular Fuzzy Comparison scale

\begin{tabular}{lrr}
\hline Linguistic scale & $\begin{array}{r}\text { Triangular } \\
\text { Fuzzy scale }\end{array}$ & $\begin{array}{r}\text { Triangular fuzzy } \\
\text { Reciprocal scale }\end{array}$ \\
\hline Just equal & $(1,1,1)$ & $(1,1,1)$ \\
Equally important & $(1 / 2,1,3 / 2)$ & $(2 / 3,1,2)$ \\
Weakly important & $(1,3 / 2,2)$ & $(1 / 2,2 / 3,1)$ \\
Strongly more important & $(3 / 2,2,5 / 2)$ & $(2 / 5,1 / 2,2 / 3)$ \\
Very strongly more important & $(2,5 / 2,3)$ & $(1 / 3,2 / 5,1 / 2)$ \\
Absolutely more important & $(5 / 2,3,7 / 2)$ & $(2 / 7,1 / 3,2 / 5)$ \\
\hline
\end{tabular}

\section{(5) Chang's extent analysis method:}

The outlines of this method for fuzzy AHP are as follows:

Letthe object set beX $=\left\{x_{1}, x_{2}, \ldots \ldots, x_{n}\right\}$ and the goal set be $U=\left\{u_{1}, u_{2}, \ldots, u_{n}\right\}$. Each object is taken and extent analysis for each goalg $g_{i}$, is performed respectively. Thus, $m$ extent analysisvalues for each object can be obtained using the following signs:

$$
M_{g_{i}}^{1}, M_{g_{i}}^{2}, \ldots \ldots \ldots, M_{g_{i}}^{k}, \quad i=1,2, \ldots \ldots \ldots \ldots, n
$$

where all the $M_{g_{i}}^{j}(j=1,2, \ldots, k)$ are triangular fuzzy numbers (TFNs) with values $l, m$, and $u$.

The steps for calculating the relative weights of criteria and alternatives using fuzzy AHP through Chang's extent analysis are as follows:

Step 1:The fuzzy pairwise comparison matrix $A=\left(a_{i j}\right)_{n \times k}$ is constructed, wherea $\mathrm{ij}_{\mathrm{ij}}$ is the relative importance of $i^{\text {th }}$ entry over $j^{t h}$ entry in pairwise comparison using triangular fuzzy numbers (TFNs), whose parameters are $l_{i j}, m_{i j}$, and $u_{i j}$. They are the least, the most, and the largest possible value, respectively, i.e. $a_{i j}=\left(l_{i j}, m_{i j}, u_{i j}\right)$ and $a_{i j}$ satisfies with following

$$
l_{i j}=\frac{1}{l_{j i}}, m_{i j}=\frac{1}{m_{j i}}, u_{i j}=\frac{1}{u_{j i}} .
$$

Step 2: The fuzzy synthetic extent's value respect toi ${ }^{\text {th }}$ object is described as:

$$
S_{i}=\sum_{j=1}^{k} M_{g_{i}}^{j} \otimes\left[\sum_{i=1}^{n} \sum_{j=1}^{k} M_{g_{i}}^{j}\right]^{-1}
$$

For calculating $\sum_{j=1}^{k} M_{g_{i}}^{j}$, the fuzzy addition method of $\mathrm{m}$ extent analysis values for an individual matrix such that: $\sum_{j=1}^{k} M_{g_{i}}^{j}=\left(\sum_{j=1}^{k} l_{j}, \sum_{j=1}^{k} m_{j}, \sum_{j=1}^{k} u_{j}\right), i=1,2, \ldots \ldots, n$

and to obtain $\left[\sum_{i=1}^{n} \sum_{j=1}^{k} M_{g_{i}}^{j}\right]^{-1}$, perform the fuzzy addition operation of $M_{g_{i}}^{j}(j=1,2, \ldots, k)$ values such that

$\sum_{i=1}^{n} \sum_{j=1}^{k} M_{g_{i}}^{j}=\left(\sum_{i=1}^{n} l_{i}, \sum_{i=1}^{n} m_{i}, \sum_{i=1}^{n} u_{i}\right)$

And then calculate the inverse's vector in Eq. (4) as follows:

$\left[\sum_{i=1}^{n} \sum_{j=1}^{k} M_{g_{i}}^{j}\right]^{-1}=\left(\frac{1}{\sum_{i=1}^{n} u_{i}}, \frac{1}{\sum_{j=1}^{k} m_{j}}, \frac{1}{\sum_{j=1}^{k} l_{j}}\right)$

Step 3: If $\mathrm{M}_{1}=\left(\mathrm{l}_{1}, \mathrm{~m}_{1}, \mathrm{u}_{1}\right)$ and $\mathrm{M}_{2}=\left(\mathrm{l}_{2}, \mathrm{~m}_{2}, \mathrm{u}_{2}\right)$ then the degree of possibility of $M_{2} \geq M_{1}$ is described as:

$V\left(M_{2} \geq M_{1}\right)$

$={ }_{y \geq x}^{\sup }\left[\min \left(\mu_{M_{1}}(x), \mu_{M_{2}}(y)\right)\right]$

and can be equivalently expressed as follows:

$V\left(M_{2} \geq M_{1}\right)=\operatorname{hgt}\left(M_{1} \cap M_{2}\right)=\mu_{M_{2}}(d)$
$=\left\{\begin{array}{cc}1, & \text { if } m_{2} \geq m_{1} \\ 0, & \text { if } l_{1} \geq u_{2} \\ \frac{l_{1}-u_{2}}{\left(m_{2}-u_{2}\right)-\left(m_{1}-l_{1}\right)}, & \text { otherwise }\end{array}\right.$

where $d$ is the ordinate of the highest intersection point Dbetween $\mu_{M_{1}}$ and $\mu_{M_{2}}$ as shown in Fig. 2 .

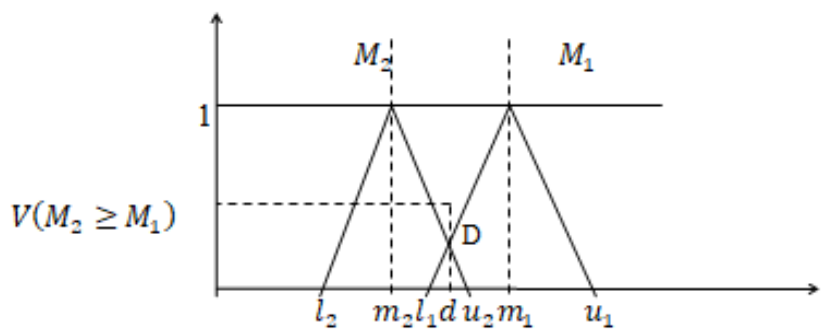

Fig. 2: Intersection of $M_{1}$ and $M_{2}$

Here, we require the values of $V\left(M_{1} \geq M_{2}\right)$ and $V\left(M_{2} \geq\right.$ $M_{1}$ ) for comparing $M_{1}$ and $M_{2}$.

Step 4: The degree of possibility for a convex fuzzy number to be greater than $k$ convex fuzzy numbers $M_{i}(i=1,2, \ldots, q)$ can be defined as:

$$
\begin{gathered}
V\left(M \geq M_{1}, M_{2}, \ldots, M_{q}\right)=V\left[\left(M \geq M_{1}\right) \text { and }\left(M \geq M_{2}\right)\right. \text { and } \\
\left.\quad \ldots . \text { and }\left(M \geq M_{q}\right)\right]=\min V\left(M \geq M_{q}\right), i=1,2, \ldots \ldots, q .
\end{gathered}
$$

Now, assume that

$d^{\prime}\left(A_{i}\right)=\min V\left(S_{i} \geq S_{q}\right)$

For $k=1,2, \ldots \ldots, n ; q \neq i$. Then the weight vector is given by 


$$
W^{\prime}=\left(d^{\prime}\left(A_{1}\right), d^{\prime}\left(A_{2}\right), \ldots \ldots \ldots, d^{\prime}\left(A_{n}\right)\right)^{T}
$$

Step 5: After normalized, is given as follows:

$W=\left(d\left(A_{1}\right), d\left(A_{2}\right), \ldots \ldots ., d\left(A_{n}\right)\right)^{T}$

where $W$ is non-fuzzy number.

The triangular fuzzy conversion scale used in this paper is shown in Table 2.In the next section, we present a numerical application of the integrated fuzzy AHP with ME-OWA, framework.

\section{NUMERICAL ILLUSTRATION}

Here objective is to select the best $\mathrm{B} 2 \mathrm{C}$ e-commerce websites on the basis of B2C e-commerce success criteria. B2C ecommerce experts were invited to obtain the fuzzy pair-wise matrices, which are required to calculate the priority weights for each criterion as described. The application is based on the following steps:

Step 1: Construct the hierarchy for the problem

The hierarchy of the problem is demonstrated in Fig. 3. The hierarchy has three levels. The goal of the selection process defined as Best B2C e-commerce website at the top level, seven criteria at the second level, and five alternatives of $\mathrm{B} 2 \mathrm{C}$ e-commerce websites are at the lowest level in the hierarchy.

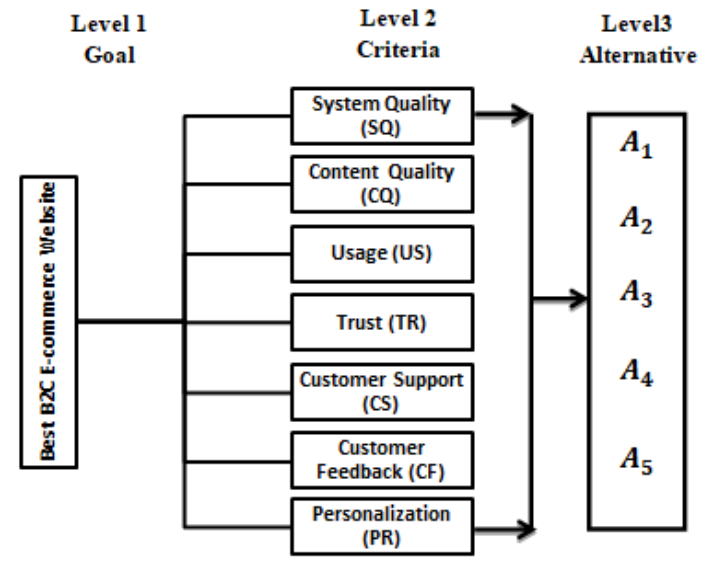

Fig 3: The hierarchy of the problem

Step2: Construct the fuzzy pairwise comparison matrix M for criteria

The fuzzy pairwise comparison matrices are obtained from B2C e-commerce experts. Using the method described in Section 3.5, the following pair-wise comparison matrices and weight vectors for alternatives respect to each criterion are obtained:

$$
M_{\mathrm{SQ}}=\left[\begin{array}{lllll}
(1,1,1) & (1,3 / 2,2) & (1 / 2,1,3 / 2) & (1,3 / 2,2) & (1,3 / 2,2) \\
(1 / 2,2 / 3,1) & (1,1,1) & (1 / 2,1,3 / 2) & (1,3 / 2,2) & (1,3 / 2,2) \\
(2 / 3,1,2) & (2 / 3,1,2) & (1,1,1) & (1,3 / 2,2) & (3 / 2,2,5 / 2) \\
(1 / 2,2 / 3,1) & (1 / 2,2 / 3,1) & (1 / 2,2 / 3,1) & (1,1,1) & (1 / 2,1,3 / 2) \\
(1 / 2,2 / 3,1) & (1 / 2,2 / 3,1) & (2 / 5,1 / 2,2 / 3) & (2 / 3,1,2) & (1,1,1)
\end{array}\right]
$$

$W_{\mathrm{SQ}}=(0.2458,0.2185,0.2458,0.1397,0.1502)$

$M_{\mathrm{CQ}}=\left[\begin{array}{lllll}(1,1,1) & (1,3 / 2,2) & (1 / 2,1,3 / 2) & (1,3 / 2,2) & (2,5 / 2,3) \\ (1 / 2,2 / 3,1) & (1,1,1) & (1 / 2,1,3 / 2) & (1,3 / 2,2) & (3 / 2,2,5 / 2) \\ (2 / 3,1,2) & (2 / 3,1,2) & (1,1,1) & (1,3 / 2,2) & (3 / 2,2,5 / 2) \\ (1 / 2,2 / 3,1) & (1 / 2,2 / 3,1) & (1 / 2,2 / 3,1) & (1,1,1) & (2,5 / 2,3) \\ (1 / 3,2 / 5,1 / 2) & (2 / 5,1 / 2,2 / 3) & (2 / 5,1 / 2,2 / 3) & (1 / 3,2 / 5,1 / 2) & (1,1,1)\end{array}\right]$

$W_{\mathrm{CQ}}=(0.2932,0.2412,0.2611,0.1972,0.0074)$

$M_{\mathrm{US}}=\left[\begin{array}{lllll}(1,1,1) & (1 / 2,1,3 / 2) & (3 / 2,2,5 / 2) & (2,5 / 2,3) & (5 / 2,3,7 / 2) \\ (2 / 3,1,2) & (1,1,1) & (1 / 2,1,3 / 2) & (3 / 2,2,5 / 2) & (2,5 / 2,3) \\ (2 / 5,1 / 2,2 / 3) & (2 / 3,1,2) & (1,1,1) & (1,3 / 2,2) & (1 / 2,1,3 / 2) \\ (1 / 3,2 / 5,1 / 2) & (2 / 5,1 / 2,2 / 3) & (1 / 2,2 / 3,1) & (1,1,1) & (2,5 / 2,3) \\ (2 / 7,1 / 3,2 / 5) & (1 / 3,2 / 5,1 / 2) & (2 / 3,1,2) & (1 / 3,2 / 5,1 / 2) & (1,1,1)\end{array}\right]$

$W_{\mathrm{US}}=(0.4287,0.3333,0.1835,0.0546,0)$

$M_{\mathrm{TR}}=\left[\begin{array}{llllll}(1,1,1) & (1 / 2,1,3 / 2) & (1,3 / 2,2) & (1,3 / 2,2) & (5 / 2,3,7 / 2) & \\ (2 / 3,1,2) & (1,1,1) & (1,3 / 2,2) & (1,3 / 2,2) & (3 / 2,2,5 / 2) \\ (1 / 2,2 / 3,1) & (1 / 2,2 / 3,1) & (1,1,1) & (1,3 / 2,2) & (1,3 / 2,2) & \\ (1 / 2,2 / 3,1) & (1 / 2,2 / 3,1) & (1 / 2,2 / 3,1) & (1,1,1) & (5 / 2,3,7 / 2) & \\ (2 / 7,1 / 3,2 / 5) & (2 / 5,1 / 2,2 / 3) & (1 / 2,2 / 3,1) & (2 / 7,1 / 3,2 / 5) & (1,1,1)\end{array}\right]$

$W_{\text {TR }}=(0.3152,0.2780,0.1942,0.2126,0)$

$M_{\mathrm{CS}}=\left[\begin{array}{llllll}(1,1,1) & (1 / 2,1,3 / 2) & (1,3 / 2,2) & (1,3 / 2,2) & (1,3 / 2,2) \\ (2 / 3,1,2) & (1,1,1) & (1,3 / 2,2) & (1,3 / 2,2) & (1,3 / 2,2) \\ (1 / 2,2 / 3,1) & (1 / 2,2 / 3,1) & (1,1,1) & (1,3 / 2,2) & (1 / 2,1,3 / 2) \\ (1 / 2,2 / 3,1) & (1 / 2,2 / 3,1) & (1 / 2,2 / 3,1) & (1,1,1) & (5 / 2,3,7 / 2) \\ (1 / 2,2 / 3,1) & (1 / 2,2 / 3,1) & (2 / 3,1,2) & (2 / 7,1 / 3,2 / 5) & (1,1,1)\end{array}\right]$

$W_{\mathrm{CS}}=(0.2370,0.2370,0.1789,0.2134,0.1337)$

$M_{\mathrm{CF}}=\left[\begin{array}{lllll}(1,1,1) & (5 / 2,3,7 / 2) & (2,5 / 2,3) & (1,3 / 2,2) & (3 / 2,2,5 / 2) \\ (2 / 7,1 / 3,2 / 5) & (1,1,1) & (1 / 2,1,3 / 2) & (1,3 / 2,2) & (1,3 / 2,2) \\ (1 / 3,2 / 5,1 / 2) & (2 / 3,1,2) & (1,1,1) & (1,3 / 2,2) & (1 / 2,1,3 / 2) \\ (1 / 2,2 / 3,1) & (1 / 2,2 / 3,1) & (1 / 2,2 / 3,1) & (1,1,1) & (2,5 / 2,3) \\ (2 / 5,1 / 2,2 / 3) & (1 / 2,2 / 3,1) & (2 / 3,1,2) & (1 / 3,2 / 5,1 / 2) & (1,1,1)\end{array}\right]$

$W_{\mathrm{CF}}=(0.5387,0.1969,0.0463,0.1823,0.0358)$

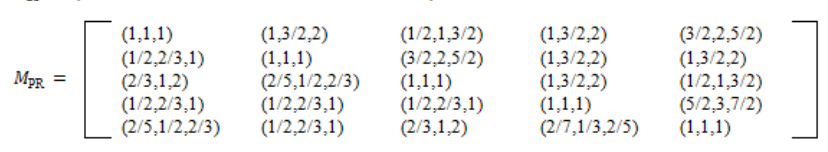

$W_{\mathrm{PR}}=(0.2987,0.2857,0.0278,0.2470,0.1490)$

Step3: Calculate and check the consistency of pair wise comparison matrices

For checking the consistency of all the fuzzy pairwise comparison matrices, we convert fuzzy matrices into crisp comparison matrices through centroid defuzzification technique called center of gravity [10]. Formula for converting the TFNs is (Wang \& Elhag, 2007):

$a_{i j}=\left(l_{i j}+m_{i j}+u_{i j}\right) / 3$, where $a_{i j}=\left(l_{i j}, m_{i j}, u_{i j}\right)$

Consistency index $(C I)$ and consistency ratio $(C R)$ need to be calculatedto check the consistency of the decision matrices. Here $C I$ and $C R$ are

given

by:

$$
\begin{aligned}
C I & =\left(\lambda_{\max }-n\right) /(n-1) \\
C R & =C I / R I
\end{aligned}
$$

where $\lambda_{\max }$ is the largest eigenvalue of the pairwise matrix, $n$ is the dimension of the matrix.The random Index $(R I)$ value proposed by Satty [14] for the different number of criterion $(n)$ is shown in Table 3.

Table 3: Relationship between random index (RI) and number of criteria (n)

\begin{tabular}{cccccccccc}
\hline$N$ & 1 & 2 & 3 & 4 & 5 & 6 & 7 & 8 & 9 \\
\hline$R I$ & 0 & 0 & 0.58 & 0.9 & 1.12 & 1.24 & 1.32 & 1.41 & 1.45 \\
\hline
\end{tabular}


Information related to the consistency of each fuzzy pairwise matrix is shown in Table 4. From Table 4, we can observe that information given by fuzzy pairwise comparison matrix is satisfactory and meet the basic requirements of consistency (as $C R<0.1$ ).

Table 4: Weights vectors for multiple criteria with $\lambda_{\text {max }}, C I$ and $C R$

\begin{tabular}{cccccccc}
\hline & SQ & CQ & US & TR & CS & CF & PR \\
\hline$A_{1}$ & 0.2458 & 0.2932 & 0.4287 & 0.3152 & 0.2370 & 0.5387 & 0.2987 \\
$A_{2}$ & 0.2185 & 0.2412 & 0.3333 & 0.2780 & 0.2370 & 0.1969 & 0.2857 \\
$A_{3}$ & 0.2458 & 0.2611 & 0.1835 & 0.1942 & 0.1789 & 0.0463 & 0.0278 \\
$A_{4}$ & 0.1397 & 0.1972 & 0.0546 & 0.2126 & 0.2134 & 0.1823 & 0.2470 \\
$A_{5}$ & 0.1502 & 0.0074 & 0.0000 & 0.0000 & 0.1337 & 0.0358 & 0.1409 \\
$\lambda_{\max }$ & 5.1025 & 5.1045 & 5.2734 & 5.1439 & 5.2786 & 5.3081 & 5.3376 \\
$C I$ & 0.0256 & 0.0261 & 0.0684 & 0.0360 & 0.0696 & 0.0770 & 0.0844 \\
$C R$ & 0.0229 & 0.0233 & 0.0610 & 0.0321 & 0.0622 & 0.0688 & 0.0754 \\
\hline
\end{tabular}

Step 4: Specify $\beta=$ orness according to Table 1 , and then obtain the $O W A$ weight vector $W=\left(w_{1}, w_{2}, \ldots \ldots \ldots, w_{n}\right)$ According to definition 2 , the value of $\beta$ i.e.orness in B2C e-commerce website selection is determined on the basis of B2C e-commerce experts' uncertain preferences. If the expert is highly optimistic on the selection of $\mathrm{B} 2 \mathrm{C}$ ecommerce websites, then the value of $\beta$ (orness)is set to be 1 . And if the expert is in the moderate state, then the value of $\beta$ (orness)is set to be 0.5 . The weight vector $W=$ $\left(w_{1}, w_{2}, \ldots \ldots ., w_{n}\right)$ of ME-OWA for a specific value of $\beta$ is given in Table 1.These values are used for aggregating the information of multiple B2C e-commerce success factors as attributes for $\mathrm{B} 2 \mathrm{C}$ e-commerce websites. In this problem, the $\beta$ (orness) is set to 0.8 because the experts' preference on the selection of B2C e-commerce websites are moderately optimistic. From Table 1, we get the weight vector as

$W=\left(w_{1}, w_{2}, w_{3}, w_{4}, w_{5}, w_{6}, w_{7}\right)$

$W=(0.4353,0.2497,0.1433,0.0821,0.0471,0.027,0.0155)$

In the next step, we calculate the OWA operators $F_{i} \forall i=$ $1,2, \ldots ., n$.with respect to each alternative.

Step 5: Calculate the OWA operator $F$ for alternatives

The maximum entropy-ordered weighted averaging aggregation (ME-OWA) operator of $A_{1}$ as $F_{1}$ is calculated as follows:

$$
\begin{aligned}
& F_{1}(\mathrm{SQ}, \mathrm{CQ}, \mathrm{US}, \mathrm{TR}, \mathrm{CS}, \mathrm{CF}, \mathrm{PR})=\sum_{i=1}^{7} w_{i} b_{i} \\
&= 0.4353 \times 0.5387+0.2497 \times 0.4287+0.1433 \times 0.3152 \\
&+0.0821 \times 0.2987+0.0471 \times 0.2932+0.0270 \times 0.2458 \\
&+0.0155 \times 0.2370=0.4354
\end{aligned}
$$

where $b_{i}$ is the $i^{\text {th }}$ largest element in the set $\{S Q, C Q, U S, T R, C S, C F, P R\}$.

Similarly, the OWA operators for $A_{2}, A_{3}, A_{4}$, and $A_{5}$ as $F_{2}=0.2962, F_{3}=0.2280, F_{4}=0.2207$, and $F_{5}=0.1230$.
Table 5: The ranking order of alternatives

\begin{tabular}{ccc}
\hline Alternative & Priority & The ranking order \\
\hline$A_{1}$ & 0.4354 & 1 \\
$A_{2}$ & 0.2962 & 2 \\
$A_{3}$ & 0.2280 & 3 \\
$A_{4}$ & 0.2207 & 4 \\
$A_{5}$ & 0.1230 & 5 \\
\hline
\end{tabular}

Now from Table 5, we can observe that $F_{1}$ is dominating all the $F_{i}{ }^{\prime} s$. Therefore, $A_{1}$ is the best selection over other alternative present in the Table 5 .

\section{CONCLUSION}

E-commerce is all about doing business electronically. In the era of internet technology, brick and mortar stores are fast being replaced by online stores, which have no geographical boundaries, save time and money, and provide an edge over the market competitors. Although e-commerce has many types but the major share of economy is encapsulated by the business-to-consumers (B2C) e-commerce. The B2C ecommerce success depends on a number of factors related with website quality and customer satisfaction.

In this paper, we present and extended e-commerce success model with includes customer oriented success criteria such as system quality (SQ), content quality (CQ), Usage (US), Trust (TR), customer support (CS), customer feedback (CF) and personalization (PR).These criteria have been used to rank a number of e-commerce websites using an integrated FAHP and ME-OWA approach. The framework used in this paper helps in capturing the uncertainty in the experts' opinion and preferences. The outcome of the paper gives the direction to the $\mathrm{B} 2 \mathrm{C}$ e-commerce customers for finding right product at right price as well as for companies to choose the best site for selling its product on the web. In the future research, we may extend our framework for optimal online advertising planning and optimal budget allocation problem.

\section{REFERENCES}

[1] Cyr, D. and C. Bonanni. Design and e-loyalty across cultures in electronic commerce. in Proceedings of the 6th international conference on Electronic commerce. ACM, (2004).

[2] DeLone, W.H. and E.R. McLean, Information systems success: The quest for the dependent variable. Information systems research. 3(1), pp. 60-95. (1992).

[3] Molla, A. and P.S. Licker, E-commerce systems success: An attempt to extend and respecify the Delone and MacLean model of IS success. J. Electron. Commerce Res. 2(4), pp. 131-141. (2001).

[4] DeLone, W.H. and E.R. McLean. Information systems success revisited. in System Sciences, 2002. HICSS. Proceedings of the 35th Annual Hawaii International Conference on. IEEE, (2002).

[5] Delone, W.H. and E.R. McLean, The DeLone and McLean model of information systems success: a ten-year update. Journal of management information systems. 19(4), pp. 9-30. (2003).

[6] Delone, W.H. and E.R. Mclean, Measuring e-commerce success: Applying the DeLone \& McLean information systems success model. International Journal of Electronic Commerce. 9(1), pp. 31-47. (2004).

[7] Chevalier, J.A. and D. Mayzlin, The effect of word of mouth on sales: Online book reviews. Journal of marketing research. 43(3), pp. 345-354. (2006). 
[8] Ghose, A. and P.G. Ipeirotis, Estimating the helpfulness and economic impact of product reviews: Mining text and reviewer characteristics. IEEE Transactions on Knowledge and Data Engineering. 23(10), pp. 1498-1512. (2011)

[9] Andreou, A.S., et al., Key issues for the design and development of mobile commerce services and applications. International Journal of Mobile Communications. 3(3), pp. 303-323. (2005).

[10] Yager, R.R., On ordered weighted averaging aggregation operators in multicriteria decision making. IEEE Transactions on systems, Man, and Cybernetics. 18(1), pp. 183-190. (1988).

[11] O'Hagan, M. Aggregating template or rule antecedents in real-time expert systems with fuzzy set logic. in Signals, Systems and Computers, 1988. Twenty-Second Asilomar Conference on. IEEE, (1988).

[12] Fullér, R. and P. Majlender, An analytic approach for obtaining maximal entropy OWA operator weights. Fuzzy Sets and Systems. 124 (1), pp. 53-57. (2001).

[13] Zadeh, L.A., Fuzzy sets. Information and control. 8(3), pp. 338-353. (1965).
[14] Saaty, T.L., The Analytic Hierarchy Process, NY. McGraw-Hill, USA. Cook WD and Seiford LM.(1978). Priority ranking and consensus formation, Management Science.24, pp. 1721-1732. (1980).

[15] Kwong, C.-K. and H. Bai, Determining the importance weights for the customer requirements in QFD using a fuzzy AHP with an extent analysis approach. Iie Transactions. 35(7), pp. 619-626. (2003).

[16] Buckley, J.J., Fuzzy hierarchical analysis. Fuzzy sets and systems. 17(3), pp. 233-247. (1985).

[17] Chang, D.-Y., Applications of the extent analysis method on fuzzy AHP. European journal of operational research. 95(3), pp. 649-655. (1996).

[18] Lee, S.-H., Using fuzzy AHP to develop intellectual capital evaluation model for assessing their performance contribution in a university. Expert systems with applications. 37(7), pp. 4941-4947. (2010).

[19] Bozbura, F.T., A. Beskese, and C. Kahraman, Prioritization of human capital measurement indicators using fuzzy AHP. Expert Systems with Applications. 32(4), pp. 1100-1112. (2007). 